\title{
Weighing the Pros and Cons of Engaging in Open Innovation
}

\section{André Ullrich and Gergana Vladova}

\author{
"A ship is safe in harbor, but that's not") \\ what ships are for.
}

William Shedd (1820-1894)

Theologian

\begin{abstract}
The positive aspects of open innovation projects are widely discussed in innovation management research and practice by means of case studies and best practices. However, enterprises, particularly small and medium-sized enterprises (SMEs) also face miscellaneous challenges in open innovation practice, leading to uncertainty and even renunciation of open innovation project participation. Thus, it is essential for SMEs to find the right balance between possible positive effects and negative consequences - the latter being the less studied "dark sides" of open innovation. However, appropriate methods of finding this balance are still lacking. In this article, we discuss the assessment of open innovation project participation by presenting a weighing and decision process framework as a conceivable solution approach. The framework includes an internal, external, and integrated analysis as well as a recommendation and decision phase. Piece by piece, we investigate the current situation and the innovation goals of the enterprise as an initial point for a decision for or against engaging in open innovation. Furthermore, we discuss the development of a software tool that automatically applies this framework and allows self-assessment by SMEs.
\end{abstract}

\section{Introduction}

The advantages of open innovation projects are widely discussed in innovation management research and practice (e.g., Man \& Duysters, 2005). Particularly, small and medium-sized enterprises (SMEs) are expected to gain most from open innovation collaborations due to their inherently limited capabilities (Lee et al., 2010; van de Vrande 2009). However, these enterprises also face manifold challenges in open innovation practice, leading to uncertainty and even renunciation of open innovation project participation. Thus, SMEs often deal with the decision dilemma of having to cooperate with external partners in order to improve their own innovation capacity, regardless of their ability to cope with the correlated risks. Although it is essential for SMEs to find the right balance between positive effects and possible negative consequences (i.e., the "dark sides" of open innovation, cf. Huizingh, 2011) of open innovation project participation, appropriate methods of finding this balance are still lacking.
The research project "Open Darkness" was initiated with the goal of enabling SMEs to weigh the risks and benefits of open innovation participation by developing: i) a weighing and decision process framework and ii) a software tool that automatically applies this framework and allows self-assessment for SMEs. Both solutions aim to structure and support the decision process regarding potential engagement in open innovation projects. In order to tackle these targeted outcomes, an interdisciplinary consortium facilitates a multi-perspective and an integrated holistic research approach. Besides several SMEs, which function as requirement authority and implementer, the consortium consists of three German research institutions: the Chair of Economic Law (University of Paderborn), the Chair of Technology and Innovation Management (University of Aachen), and the Chair of Business Informatics (University of Potsdam).

Given the importance of strategic thinking and of tacit knowledge in decision making, decision outsourcing 


\section{Weighing the Pros and Cons of Engaging in Open Innovation}

\section{André Ullrich and Gergana Vladova}

from a person to a software-based solution is inherently erroneous. Accordingly, it is explicitly not intended within the software tool to automate and process decisions, thereby removing human responsibility. It is envisaged to reduce insecurity in decision making for open innovation participation by providing a support structure that identifies causalities and alternatives and leads to the identification of action alternatives. Furthermore, the use of the tool is beneficial not only for the decision makers: given the fact that "innovation is a team sport" and employees "must be prepared to change their way of thinking" (Valkokari, 2015), it can also provide a basis for deeper understanding regarding the new aspects of the innovation process.

The goal of the present article is to discuss the assessment of potential open innovation project participation against the background of the impossibility to either predict the future or to capture all necessary environmental information as well as the serious need of SMEs for aid in this matter. This discussion will be conducted by explicating a weighing and decision process framework as a conceivable solution approach.

The remainder of the article is organized as follows. First, we emphasize the relevant theoretical aspects of open innovation. Next, we describe the methodological approach used within the study. Then, we describe the solution approach. Finally, we provide conclusions.

\section{The Bright and Dark Sides of Open Innovation}

According to conventional understanding, the primary success factors in innovative enterprises are their employees, R\&D divisions, and fault-tolerant corporate cultures. This kind of innovation refers to the closed innovation paradigm (Chesbrough, 2003). Due to an increasing trend towards globalization, new market participants, and simultaneously shorter product life- cycles with correspondingly increasing $R \& D$ costs, the closed innovation paradigm was superseded last century (Gerybadze \& Reger, 1999) by the theory of open innovation, which emphasizes the significantly higher importance of external resources (Chesbrough, 2003).

Open innovation is "the use of purposive inflows and outflows of knowledge to accelerate internal innovation" (Chesbrough et al., 2006). Thus, open innovation can be described as an interactive and collaborative innovation process with external partners (Veer et al., 2013). The positive aspects of open innovation for SMEs are widely discussed (Lee et al., 2010). Table 1 depicts some of the "bright sides" of open innovation structured into organizational, knowledge management, and legal aspects.

Comparatively, the so-called "dark sides" of open innovation processes - as shown in Table 2 - have thus far been neglected. Notably, the legal aspects are typically not structured or placed under the umbrella of open innovation research (Müller, 2013).

\section{Evaluation in innovation management}

Broad evaluation is a crucial challenge of innovation management (cf. Adams et al., 2006), particularly for assessing an enterprise's situation and developing suitable improvement measures. Existing approaches focus either on isolated aspects of innovation management, such as idea evaluation, or they consider the innovation process as an internal activity (Afuah, 2003). They can, however, be adapted for open innovation processes.

Business modelling with a focus on knowledge-intensive processes (such as innovation processes) provides another path to analyze and evaluate the current situation in an enterprise. Although the open innovation literature describes innovation processes with specific phases, in reality, SMEs innovation processes are often

Table 1. The bright sides of open innovation (Chesbrough et al., 2006; Lee et al., 2010; Veer et al., 2010)

\begin{tabular}{|c|c|c|}
\hline Organizational & Knowledge Management & Legal \\
\hline $\begin{array}{l}\text { - Diversification of R\&D investments } \\
\text { - Easier market entry } \\
\text { - Resource acquisition advantages }\end{array}$ & $\begin{array}{l}\text { - Broader base of ideas } \\
\text { - Technological synergy effects } \\
\text { - Improvement of the internal } \\
\text { learning capacity through the } \\
\text { transfer of external knowledge and } \\
\text { learning routines }\end{array}$ & $\begin{array}{l}\text { - Use of intellectual property as } \\
\text { strategic assets } \\
\text { - Monitoring of the uncertainty of } \\
\text { value and protection level of others' } \\
\text { patents }\end{array}$ \\
\hline
\end{tabular}




\section{Weighing the Pros and Cons of Engaging in Open Innovation}

\section{André Ullrich and Gergana Vladova}

Table 2. The dark sides of open innovation (Enkel et al., 2009; Müller, 2013; Veer et al., 2013)

\begin{tabular}{|c|c|c|}
\hline Organizational & Knowledge Management & Legal \\
\hline $\begin{array}{l}\text { - } \text { Process coordination costs } \\
\text { - Implementation costs } \\
\text { - More faults in routine workflows }\end{array}$ & $\begin{array}{l}\text { - Strong dependence on external } \\
\text { knowledge } \\
\text { - Loss of key knowledge control } \\
\text { - Loss of flexibility, creativity, and } \\
\text { strategic power }\end{array}$ & $\begin{array}{ll}\text { - } & \text { Lack in legacy for additional tasks } \\
\text { - } & \text { Intellectual property spillover } \\
\text { - } & \text { Different levels of contractual } \\
\text { experience compared to big } \\
\text { enterprises (as potential partners) }\end{array}$ \\
\hline
\end{tabular}

unstructured. Thus, such an analysis is an essential starting point for evaluating knowledge and information flows, business processes and personnel interactions (Gronau, 2012).

\section{Research Approach}

The openness of innovation processes is associated with uncertainty regarding positive and negative consequences of the project design. Thus, enterprises often need methodical support within the decision process of open innovation project participation. However, according to our review of the literature, no approaches exist for weighing the risks and benefits of open innovation project participation.

The lack of a decision support framework for weighing benefits and risks of open innovation participation leads to the contributions' underlying question:

In terms of the development of a self-assessment software tool for SMEs - to evenly capture, analyse, and weigh chances and risks of open innovation projects how should a weighing and decision process framework be designed?

\section{Methodological approach within the study}

To ensure theoretical and practical relevant aspects within the weighing and decision process framework and the software tool are not neglected, our research design includes a combination of qualitative, quantitative, and software development methods:

1. A literature review on the following topics: phases and evaluation of open innovation processes in SMEs, internal and external knowledge interfaces, conditions of participation, measures for participation and risk reduction, and positive and negative aspects of open innovation.
2. Modelling and analysis of existing open innovation processes for 15 SMEs, on the basis of more than 35 interviews with decision makers and employees. The main result of this second step, combined with the first step (i.e., the literature review) is the identification of open innovation process assessment indicators for SMEs including knowledge management, organizational, and legal aspects.

3. Indicator evaluation, through a survey and interviews with open innovation experts. Part of this step is the establishment of a community of open innovation experts, which acts as a supervisory body and validation group.

Applying the results of these three theoretical steps, the following conceptual tasks are addressed:

4. Development of a methodological procedure in the form of a weighing and decision framework with the aid of an evaluation catalogue, ratio systems, and implementation procedure models for SMEs.

5. Implementation of the methodological procedure within a self-assessment tool. This step includes a determination of requirements based on the results of the previous and the actual development of the tool based on the scrum software development framework. Scrum (Sutherland \& Schwaber, 2013) is an agile software development framework that is based on rules that define five activities (sprint planning, daily scrum, sprint review, sprint retrospective, product backlog refinement), three artefacts (product backlog, sprint backlog, product increment), and three roles (product owner, development team, scrum master) (cf. Beedle \& Schwaber, 2002). Due to ongoing group discussion and reflection at the end of each work phase, a continuous improvement process ensures a positive effect on the technical results. 


\title{
Weighing the Pros and Cons of Engaging in Open Innovation
}

\author{
André Ullrich and Gergana Vladova
}

\section{Approaching a Solution}

Besides the theoretical outcomes that result from the first three steps of the methodology as a state-of-the-art extension, the second main emphasis of the project lies in the implications of the results on enterprise practice. This second aspect is addressed by the development of the software tool on the basis of the weighing and decision process framework. Due to the wide heterogeneity of open innovation situations and innovation processes, it would be foolhardy to assume that a software tool (as a main outcome) could take the entrepreneurial decision and, thereby, simply solve the complex decision problem of open innovation participation. However, the special value of the tool is the possibility to assist SME innovation managers by guiding them through the self-assessment weighing and decision process in the run-up of a potential new open innovation project.

In the given situation, decision makers and innovation managers are confronted with strategic and operative challenges, such as:

-What are our (innovation) goals?

- To what extent are we willing to take risks?

- How structured is the current (open innovation) process?

- How open could and should the innovation process be?

-What specific risks exist regarding potential partners and knowledge and information losses?
-What is the level of preparation required to avert these risks?

-What kind of improvement can be expected from cooperation with external partners?

These and further questions are addressed by the weighing and decision process framework. The process can be structured in five steps, which are described and exemplified below and in Figure 1.

As a starting point of the process, three different aspects are evaluated with the active involvement of the enterprise:

1. Identification of innovation goal, degree of innovation, risk propensity, and strengths and weaknesses analysis (a general analysis aspect, irrespective of a concrete open innovation project): Primary and secondary value chain activities constitute the framework to identify enterprises' specific open innovation strengths and weaknesses (e.g., innovation project experience, own innovation process structure, resource allocation). Applying the software tool, profile tables, and process analysis models will be used for these queries. The innovation goal will be divided into output, input, and process goals. The degree of innovation will be assessed as incremental or radical and according to corporations' innovation intensity. The risk propensity categories are: risk seeking, risk averse, and risk neutral. These aspects will be queried by closed direct or indirect questions.

2. Identification of benefits and risks as well as assessment of their occurrence probability (analysis aspect

\section{Internal \\ Analysis \\ External \\ Analysis \\ Integrated \\ Analysis}

- Innovation goal
- Risk propensity
- Degree of
Innovation

Strength and

Weakness Analysis

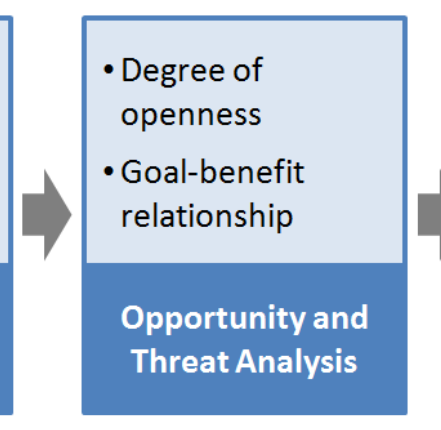

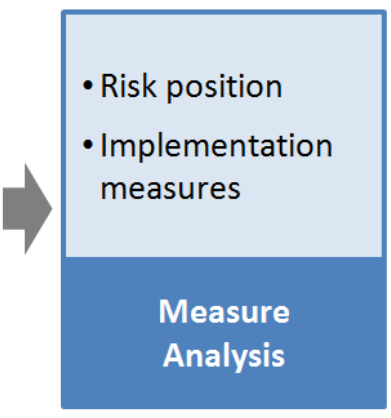

\section{Recommendation Phase}

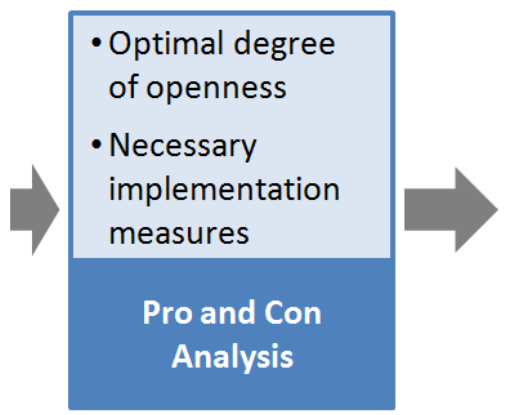

Decision

Phase

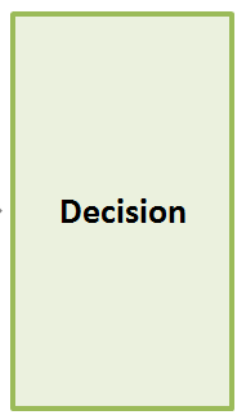

Figure 1. Analysis and decision process framework 


\title{
Weighing the Pros and Cons of Engaging in Open Innovation
}

\author{
André Ullrich and Gergana Vladova
}

with regard to a concrete open innovation project): Specific risks and benefits of open innovation cooperation will be prompted using a predefined catalogue. Additionally, their respective occurrence probability will be estimated by indirect closed questions, for example, regarding past experiences with project partners, criticality of knowledge and information, and assessment of their actual situation and existing protection measures.

Within phase 1 and 2, indirect questions will be used to determine the enterprise's ideal degree of openness. In addition, enterprises will be enabled to specify their open innovation goals and relate specific project benefits directly to them.

\section{Assignment of measures to benefits and risks (analysis} aspect with regard to a concrete open innovation project): Analytical findings will be considered to identify potential need for and comparative advantages of protection measures. They provide the basis for the assignment of relevant measures. If each risk and each benefit can be associated with corresponding specific measures in order to either avoid or enable them, then: i) already existing enabling or protection measures within the enterprise will be discovered and ii) missing measures and necessary investments and efforts for their establishment will be revealed. Based on the present innovation process structure, potential partner profiles, knowledge and information flows, and legal situations, the enterprise' risk position will be clarified.

Within the next steps, the enterprise-specific information gained within the three analysis phases will be evaluated automatically by the software and with no need for the active involvement of the enterprise.

4. Presentation of analysis results: Based on the evaluation of the aforementioned steps, three major results will be depicted: i) the optimal degree of openness (by the aid of a type classification proximity/formalization [Diener 2015]); ii) expectable efforts for necessary, promising, and risk propensity dependent measures to enable context-specific optimal degrees of openness and innovation; and iii) depiction of advantages and disadvantages of the open innovation corporation project under consideration.

5. Come to a decision: Condensed information will be provided as a basis for the decision to be made.
To sum up, the analysis and decision process framework fulfils three functions: i) provision of understanding for the present situation and, within this, ii) reduction of the perceived risk of open innovation project participation, and iii) general recommendation for action, which serves as decision support for the innovation manager. Within the five steps, different information is requested in order to deduce the enterprise specific initial situation and target goals. Part of the information can be used repeatedly within the decisionmaking process regarding different open innovation projects. However, some analysis content should be estimated de novo for every open innovation project.

The framework and the software tool provide a broad, evaluative foundation to assist with the complexity of the decision-making process. However, acting on their own, the software tool can prepare the information basis and formulate concrete recommendations but cannot provide a definitive answer to the ultimate question of whether or not to participate in an open innovation project.

\section{Conclusions and Outlook}

After establishing the theoretical background, approach, and process model, the next steps include their evaluation from the practical point of view. This is ensured by a close collaboration with enterprises (especially SMEs) and innovation experts and includes two evaluation focuses. First, the innovation indicators developed (see step 3 above) will be evaluated according to their importance within open innovation projects. Given the mostly theoretical nature of these indicators, this step is necessary in order to preserve their relevance and applicability within the practice of the enterprise. For this purpose, innovation experts will be asked to estimate and appraise the indicators on the basis of their practical experience. The indicators selected build the base for the development of the weighing and decision framework. After the implementation of the framework into the software tool, a second evaluation of both - the potentiality and functionalities of the tool - will be carried out in form of a test phase.

Whether a decision made in doubt was really good, accurate, or solely sub-optimal, remains highly subjective, simply because of the lack of the opportunity to compare real-world situations. There is only one realtime occurrence and no reliable further information about alternative scenario developments available. 


\section{Weighing the Pros and Cons of Engaging in Open Innovation}

\section{André Ullrich and Gergana Vladova}

Thus, guiding entrepreneurial decision processes is particularly beneficial in order to reduce insecurity (Simon, 1979) as a reason not to participate in an open innovation project. Given that risk awareness is of particular importance for enterprises, it is pivotal to provide an understanding that their "risks are greater if they choose not to innovate" (Valkokari, 2015).

Although there is a plenty of research dealing with the assessment of the positive aspects of open innovation processes as well as some research with emphasis on the "dark sides" of open innovation, the novelty of this approach is the analysis of the interdependencies of both facets and their combined impact on the open innovation project's chances of success.

SMEs are particularly addressed because they are economical backbones and will benefit more than corporations with economies of scale. Although facing similar challenges, each is unique and requires tailored recommendations for improvement.

\section{Acknowledgements}

The project Open Darkness (IGF promotion plan 18632 of the Institut für Energie- und Umwelttechnik (IUTA)), is funded by the AiF within the programme for sponsorship by Industrial Joint Research and Development (IGF) of the German Federal Ministry of Economic Affairs and Energy.

An earlier version of this article was presented at the 2015 ISPIM Innovation Summit in Brisbane, Australia, December 6-9, 2015. ISPIM (ispim.org) - the International Society for Professional Innovation Management - is a network of researchers, industrialists, consultants, and public bodies who share an interest in innovation management.

\section{About the Authors}

André Ullrich has worked as a Research Assistant and a PhD Candidate at the Chair of Business Informatics with an emphasis on Processes and Systems at the University of Potsdam, Germany, since graduating there with a Diploma in Business Administration in 2011. Currently, his research interests are open innovation processes, employee qualification, the performance capability of indicators for assessing organizations, and change capability research. Furthermore, he continuously moderates creativity workshops regarding turbulences in business environments. He has published several national and international articles in the research areas of change capability, creativity techniques, seasonality's, and employee qualification.

Gergana Vladova is a Research Assistant and a $\mathrm{PhD}$ Candidate at the Chair of Business Informatics with an emphasis on Processes and Systems at the University of Potsdam, Germany. She holds a Master's degree in International Economic Relations from the University of National and World Economy in Sofia, Bulgaria, and a Magister degree from the Freie Universitît Berlin, Germany. She has been working within diverse research projects, and she lectures graduate courses and seminars in the field of knowledge management. Her main fields of research are corporate communication and culture, knowledge management, product counterfeiting, and open innovation management. 


\section{Weighing the Pros and Cons of Engaging in Open Innovation \\ André Ullrich and Gergana Vladova}

\section{References}

Adams, R., Bessant, J., \& Phelps, R. 2006. Innovation Management Measurement: A Review. International Journal of Management Reviews, 8(1): 21-47.

http://dx.doi.org/10.1111/j.1468-2370.2006.00119.x

Afuah, A. 2003. Innovation Management: Strategies, Implementation and Profits. Oxford: Oxford University Press.

Beedle, M., \& Schwaber, K. 2002. Agile Software Development with Scrum. Upper Saddle River, NH: Prentice Hall.

Chesbrough, H. 2003. Open Innovation: The New Imperative for Creating and Profiting from Technology. Boston, MA: Harvard Business Press.

Chesbrough, H., Vanhaverbeke, W., \& West, J. (Eds.). 2006. Open Innovation: Researching a New Paradigm. Oxford: Oxford University Press.

Diener, K. 2015. Organizing Collaborative Innovation: Studying the Process of Intermediaries for Open Innovation. Doctoral Dissertation. RWTH Aachen University.

Enkel, E., Gassmann, O., \& Chesbrough, H. 2009. Open R\&D and Open Innovation: Exploring the Phenomenon. $R \& D$ Management, 39(4): 311-316.

http://dx.doi.org/10.1111/j.1467-9310.2009.00570.x

Gronau, N. (Ed.) 2012. Modeling and Analyzing Knowledge Intensive Business Processes with KMDL: Comprehensive Insights into Theory and Practice. Berlin: GITO Verlag.

Huizingh, E. 2011. Open Innovation: State of the Art and Future Perspectives. Technovation, 31(1): 2-9.

http://dx.doi.org/10.1016/j.technovation.2010.10.002
Lee, S., Park, G., Yoon, B., \& Park, J. 2010. Open Innovation in SMEs An Intermediated Network Model. Research Policy, 39(2): 290-300. http://dx.doi.org/10.1016/j.respol.2009.12.009

de Man, A.-P., \& Duysters, G. 2005. Collaboration and Innovation: A Review of the Effects of Mergers, Acquisitions and Alliances on Innovation. Technovation, 25(12): 1377-1387.

http://dx.doi.org/10.1016/j.technovation.2004.07.021

Müller, S. 2013. Innovationsrecht - Konturen eines Rechtsgebiets, Zeitschrift für Innovations- und Technikrecht (InTeR), 1 2, 58-71.

Simon, H. A. 1979. Rational Decision Making in Business Organizations. The American Economic Review, 69(4): 493-513. http://www.jstor.org/stable/1808698

Sutherland, J., \& Schwaber, K., 2013. The Scrum Guide: The Definitive Guide to Scrum - The Rules of the Game. ScrumGuides.com. Accessed April 1, 2016: http://www.scrumguides.org/scrum-guide.html

Valkokari, K. 2015. Q\&A. In the Innovation Game, Why Do So Many Companies Stay on the Sidelines? Technology Innovation Management Review, 5(11): 35-39. http://timreview.ca/article/944

van de Vrande, V., de Jong J. P. J., Vanhaverbeke, W., \& de Rochemont, M. 2009. Open Innovation in SMEs: Trends, Motives and Management Challenges. Technovation, 29(6-7): 423-437. http://dx.doi.org/10.1016/j.technovation.2008.10.001

Veer, T., Lorenz, A., \& Blind, K. 2013. How Open Is Too Open? The "Dark Side" of Openness along the Innovation Value Chain. Paper Presented at the 35th DRUID Celebration Conference, Barcelona, Spain, June 17-19. 